\title{
Endovascular Application of Low-Energy Laser in the Treatment of Dyscirculatory Angiopathy of Alzheimer's Type
}

\author{
Ivan V. Maksimovich \\ Clinic of Cardiovascular Diseases Named after Most Holy John Tobolsky, Moscow, Russia \\ Email: carvasc@yandex.ru
}

Received September 20, 2011; revised December 2, 2011; accepted December 15, 2011

\begin{abstract}
Purpose: We propose an analysis of dyscirculatory angiopathy of Alzheimer's type (DAAT) endovascular treatment method based on transcatheter revascularization and recovery of collateral and microvascular bed of the brain by means of low-energy transluminal laser irradiation as well as its comparison with traditional Alzheimer's disease (AD) treatment methods. Methods: The research involved 81 patients aged 34 - 79 (average age 67). 46 (46.8\%) patients were treated using endovascular method-Test Group. $35(43.2 \%)$ patients were given conventional treatment-Control Group. Patients were subdivided: Group (CDR-0): 9 (11.1\%), pre-clinical stage or increased AD risk; Group (CDR-1): 24 (29.6\%), mild dementia and cognitive impairment; Group (CDR-2): 31 (38.3\%), moderate dementia and persistent cognitive impairment; Group (CDR-3): 17 (21.0\%), severe dementia and cognitive impairment. Research plan included CT or MRI with subsequent temporal lobes volume calculation, brain scintigraphy (SG), rheoencephalography (REG), and cerebral MUGA. There were indications and contraindications for treatment in Test Group. In Group CDR-0, endovascular intervention was prophylactic, against the background of increasing memory impairment; in Groups CDR-1, CDR-2, CDR-3, it was conducted in 1 to 12 years period from AD symptoms appearance. Conservative treatment with Memantin and Rivastigmine was carried out in Control Group. Results: In Test Group, positive outcome accompanied by prolonged dementia decline, cognitive impairment decrease, and patients' transition to CDR group of an earlier stage, was obtained in all cases. In Control Group, patients' temporary stabilization in their own CDR group was achieved. Conclusions: Endovascular treatment of patients with AD different stages can not only reduce DAAT phenomena but can also cause $\mathrm{AD}$ regression possibly accompanied by regenerative processes in the cerebral tissue. Conservative treatment only allows stabilizing the patient's condition for a while.
\end{abstract}

Keywords: Alzheimer's Disease; Dementia; Dyscirculatory Angiopathy of Alzheimer's Type; DAAT; Hippocampus; Temporal Lobes Atrophy; Hypovascular Zone; Laser Revascularization; Brain Tissue Regeneration

\section{Introduction}

In recent decades, Alzheimer's disease (AD) has been more and more widespread among the world population. According to the Alzheimer's Association, AD is becoming a global problem of mankind affecting people of virtually all countries regardless of ethnicity and socio-economic status. Thus, 5.1 million cases were registered in the United States in 2007 [1], 5.4 million-in 2011 [2], and it is estimated that this number will increase to 13.5 million by 2050 [3]. Moreover, in case of diagnosing preclinical stages of the disease, the number will yet rise significantly. 35.6 million cases were registered around the world in 2010; by 2050 this figure may grow up to 115.4 million, and every second person at the age of 85 and older will suffer from $\mathrm{AD}$ [4].

Despite the fact that etiology and pathogenesis of $\mathrm{AD}$ have not been fully studied so far [5], the diagnosis of pre-clinical and early forms of the disease was named one of the major foci in AD studies at AAIC 2011. Such diagnosis will make possible an early treatment which is naturally more effective [6]. It is already known that sufficiently rare, genetically determined forms of $\mathrm{AD}$ are characterized by certain chemical changes in the brain which may appear 10 - 20 years before the initial clinical manifestations of the disease [7]. Genetically unconditional $\mathrm{AD}$ is also characterized by pre-clinical initial changes in the brain tissue, though their intensity is low [8]. It is fairly difficult to diagnose pre-clinical stages when the disease has not yet developed and the manifestations of dementia and cognitive impairment are mild or altogether absent [8-12]. At its early stages, AD is hard to differenttiate from other diseases accompanied by dementia and 
mild cognitive impairment (MCI), and, as a result, a clinically correct diagnosis is not always possible [13,14].

For a long time AD research has mainly focused on morphological and structural defects developing in the brain tissue. CT and MRI have allowed diagnosing atrophic changes in the temporal lobes and the hippocampus at later stages of $\mathrm{AD}[15,16]$. The introduction of PET and biomarkers has allowed devising a large number of different automated methods for determining the quantitative, qualitative, and functional changes that develop in $\mathrm{AD}$ affected temporal lobes and hippocampus. Besides, these methods have made possible to visualize the accumulation of amiloid-beta and tau, but this highly promising direction of research is still in its development stage and requires further standardization and study [8,17-20]. In some cases, high level of amyloid does not always lead to the development of AD.

First reports of vascular changes in $\mathrm{AD}$ affected brain were made in the 1930 s by F. Morel who named these changes dysoric or drusoidal angiopathy [21]. In recent years, there have been a lot of large-scale studies on the vascular factor in the development of AD [5,22-27], cerebral blood flow disorders [28,29], and the phenomena of amyloid angiopathy [30-33].

Quite often the problem is discussed in terms of the location of amyloid deposit, the influence of concomitant diseases such as diabetes and hypertension, but not in terms of the development of vascular disorders. Insufficient attention is still paid to the correlation of vascular and degenerative changes that develop in the brain tissue and to their joint effect on dementia and cognitive impairment [34].

Certain studies report that AD is characterized by practically absent or poorly expressed atherosclerotic changes of intracranial arteries, but the disease is almost always, regardless of the stage, accompanied by specific arterial, venous and microcirculatory disorders in the temporal and fronto-parietal brain regions, which were named “dyscirculatory angiopathy of Alzheimer's type" (DAAT) [27,34-36].

These disorders are manifested by reduction of the capillary bed in the temporal and fronto-parietal regions leading to the development of vast hypovascular areas [34]. In the same regions there develop early arteriovenous shunts causing early venous shunts [35]. At the same time, due to the venous shunts, there develop abnormally enlarged vein branches that contribute to venous stasis in the corresponding areas [36]. Besides, large looping is noted in the distal parts of the anterior and middle cerebral arteries [27].

$\mathrm{AD}$ is difficult to treat; specific drugs affecting the amyloid are mainly under development, and therefore patients most often undergo a neuroprotective, cholinergic, symptomatic therapy which is not always effective [37].

\section{Materials and Methods}

The whole research and all the endovascular intervenetions are made with the approval of the Ethics Committee and with the consent of the examined and treated patients and their relatives.

The research involved 81 patients aged from 34 to 79 (average age 67) including $28(34.57 \%)$ male and 53 (65.43\%) female patients; 72 of them had been previously diagnosed with AD. Patients with a pre-clinical stage or a high risk of developing the disease comprised a specific group of $9[27,34]$.

$46(56.8 \%)$ patients underwent endovascular treatment - Test Group.

$35(43.2 \%)$ patients underwent conservative treatment Control Group.

Selection criteria for patients:

1) Consent of the patient and his/her relatives for the examination and treatment;

2) The patient's somatic condition allowing the examination and treatment;

3) The severity of dementia, cognitive disorders, the state of higher mental functions, social adjustment, and intelligence; severity of memory impairment;

4) The severity of atrophy and vascular changes in the temporal and fronto-parietal lobes of the brain.

The groups consisted of patients without severe concomitant diseases which do not allow examination and treatment, and with relatively satisfactory somatic state in accordance with their age.

Significant cardiac abnormalities, somatic disorders, severe forms of diabetes were considered contraindications for treatment.

Before, during and after the treatment the social level as well as the nutritional status of the patients did not change.

The general research plan included: CT of the brain (CT), magnetic resonance imaging (MRI), scintigraphy of the brain (SG), rheoencephalography (REG), cerebral multi-gated angiography (MUGA), laboratory diagnosis, assessment of cognitive functions (MMSE). As genetically determined forms of AD are sufficiently rare [7], genetic examination of patients was not included in the research plan. Considering the fact that $\mathrm{AD}$ affects all segments of population [1], sociological examination of the patients was not included in the research plan.

In the research, CT was preferred over MRI to identify the nature of vascular disorders and to better visualize calcium salts deposits in the walls of cerebral arteries in case of atherosclerotic lesions [12,16,24]. The research mostly focused on the study of the changes in the temporal lobes and the hippocampus as they are the first to suffer during the development of $\mathrm{AD}$ and as they are fairly easy because of the bone formations - visualized by CT [12,36].

CT of the brain was performed on apparatus "Somatom" (Siemens), "HiSpeed" (GE), “Tomoscan" (Philips) 
by the following procedure $[12,16]$. The orbital-miotal line was considered the boundary of the first scan. The scans were $2.5 \mathrm{~mm}$ thick and taken at an interval of $2.5 \mathrm{~mm}$. The boundaries of cerebral fosses on both sides were ascertained by bone marks. A consistent two-side measurement of cerebral fosses region and measurement of the size of the substance of the right and left temporal lobes of the brain for each scan were made with computer program "Advanced Tomo Area Analysis" (ATAA). Next, the area of the lower horn of lateral ventricle and the area of the sulci were subtracted and then compared with the area of the corresponding cranial fossa at the same level. The ratio of these quantities allows comparing the state of the brain tissue both in its normal condition and when developing atrophic processes. Brain tissue area reducetion at each scan corresponds to the severity of atrophic changes at this level of the brain. Then the above mentioned quantities were automatically recalculated by the thickness of each scan and each interval between the scans, and the volume of the right and left temporal lobes of the brain was determined, and thus the mass of the brain tissue in the surveyed areas was calculated. Next, the masses of tissue of the left and right temporal lobes were summed up. The results of the research automatically showed both the normal amount of the tissue for the corresponding age group and the percentage decrease of the volume of the temporal lobes of the brain. The percentage ratio of those values determined the severity of atrophic changes.

Due to the fact that examined patients belonged to different age groups, the research took into account age-related changes in the brain tissue. For example, if patients aged 60 and older had general atrophic brain changes with a decrease in the size of the temporal lobes of up to $5 \%$, it was considered natural age-related changes and equal to normal $[12,36,38]$. The calculation of volume changes of the whole temporal lobe of the brain gives more accurate results of the severity of atrophic changes than calculation of atrophic changes of only the hippocampus, which is confirmed by studies of other authors [39].

Since all classifications of AD types and stages are functional in nature and are not based on morphological changes, we have altered J. C. Morris's classification of 1993 (The Clinical Dementia Rating) [40] introducing into it a morphological component. Patients were divided into groups according to the degree of the severity of atrophic changes in the temporal lobes of the brain, as well as the severity of dementia, cognitive disorders, and the severity and duration of the disease.

In contrast to the classification proposed by J. C. Morris which originally regarded the earliest stage of the disease as the CDR-0.5, our classification has introduced a pre-clinical stage of CDR-0. The conclusions of AAIC 2011 underline the necessity of introducing the preclini- cal stage. It should also be mentioned that J. C. Morris himself introduced a group of CDR-0 later [8].

Inside their CDR group, patients of the Test and Control Groups did not differ initially by the state of their cognitive and higher mental functions and the severity of dementia.

As a result, examined and treated patients were divided into:

- Group CDR-0: patients with an increased risk of AD development (preclinical stage), who, along with memory disorders, revealed atrophic changes in the temporal lobes of the brain manifested by a decrease in the tissue mass of $4 \%-8 \%$. This group consisted of the relatives of patients with AD. These people were fairly young, aged from 34 to 42; they were not diagnosed with $\mathrm{AD}$ but had growing memory disorders without manifestations of dementia or any special cognitive impairment; and their two or more immediate relatives suffered from AD. All these patients wished to be examined and treated for preventive purposes. Test Group-4 (4.9\%) patients, Control Group$5(6.2 \%)$ patients;

- Group CDR-1: patients aged 40 to 62 with mild dementia, mild cognitive impairment, early clinical stage of the disease, medical history of up to 2 years, atrophic changes of the temporal lobes with a decrease in the tissue mass of $9 \%-18 \%$; Test Group - 15 (18.5\%) patients, Control Group-9 (11.1\%) patients;

- Group CDR-2: patients aged 56 to 69 with moderate dementia and persistent cognitive impairment, middle clinical stage of the disease, medical history of 2 to 6 years, atrophic changes of the temporal lobes with a decrease in the tissue mass of 19-32\%; Test Group$20(24.7 \%)$ patients, Control Group-11 (13.6\%) patients;

- Group CDR-3: patients aged 65 to 79 with severe dementia, gross cognitive impairment, late clinical stage of AD, medical history of 6 to 12 years, severe atrophic changes of the temporal lobes accompanied by a decrease in the tissue mass of $33 \%-62 \%$; Test Group-7 (8.6\%) patients, Control Group-10 (12.3\%) patients.

Almost all the patients had atrophic changes in the temporal lobes of the brain along with the extension of Sylvian fissures and subarachnoidal space in the temporal and fronto-parietal regions. The degree of the atrophic changes was almost in direct proportion to the stage of the disease, the severity of dementia and cognitive impairment, and the patient's condition.

SG of the brain was carried out on a gamma camera (Ohio Nuclear, U.S.) following the classical method in the dynamic and static mode using TC 99M pertechnetat 555.

According to SG, the slowing of the blood flow in the 
cerebral hemispheres to Tmax $9-10 \mathrm{sec}, \mathrm{T} 1 / 210-11$ sec was observed in $51(63.0 \%)$ cases; to 12 Tmax $13 \mathrm{sec}$, $\mathrm{T} 1 / 215-20 \mathrm{sec}$ - in $30(37.0 \%)$ cases.

REG was conducted on rheograph "Reospektr- 8 " (Neurosoft, Russia) in accordance with the standard automated method with the determination of pulse blood filling disorders.

According to the REG data, a decrease in pulse blood volume in the carotid areas of $15-20 \%$ was detected in 49 $(60.5 \%)$ cases; of $40 \%-50 \%$ - in $32(39.5 \%)$ cases.

MUGA of the brain was performed on apparatus "Advantx" (GE) following the classical method of transfemoral access. Simultaneously, taking into account the beginning and the rate of administration, $10-12 \mathrm{ml}$ of $\mathrm{Om}$ nipack 350 was introduced intra-carotidally and $7-8 \mathrm{ml}$ intra-vertebrally. Registration was carried out in direct and side projections in the constant subtraction mode at a speed of 25 frames per second. Then the angiograms obtained were analyzed frame by frame in each phase contrast $[12,36]$. The analysis of capillary density was carried out in the relevant phase by an automatic method using the "Angio Vision" computer program based on determining the degree of blackening the corresponding section of the image [12,36].

Laboratory examination was carried out by conventional interventional radiology schemes and included clinical, biochemical and coagulogic examination.

The evaluation of cognitive impairment and mental state of the treated patients was conducted by the MiniMental State Examination (MMSE). The initial testing was performed during a patient's first examination or on the day of his/her hospitalization. Repeated testing was carried out on the day of the patient's discharge, and then at intervals of $6-12$ months.

MUGA showed that all the examined patients had little or no pronounced atherosclerotic changes of extra and intracranial arteries. The reduction of capillary phase contrast in the form of vascular cone-shaped sites in the frontoparietal regions and in the hippocampus projection was found in all 47 cases. Multiple arteriovenous shunts in the basin of arterial branches supplying the fronto-parietal brain regions and in the basin of front villous artery supplying the hippocampus accompanied by early venous shunts were observed among all patients. The development of lateral abnormally enlarged veins that receive blood from arteriovenous shunts forming in the temporal and fronto-parietal regions was observed among 42 (89.4\%) patients. Anomalous venous congestion at the border of the frontal and parietal lobe was observed among 43 $(91.5 \%)$ patients. Increased looping of distal branches of anterior and middle cerebral arteries was noted among 37 (78.7\%) patients.

\section{DAAT Endovascular Treatment Method [41-44]}

Under local anesthesia, according to Seldinger's classical method, the common femoral artery is punctured and catheterized by installing an introducer with a diameter of 6-9F. Through this introducer and through coaxially guided guiding catheters installed in the general and further on in the internal carotid artery, is brought a flexible fiber-optic laser instrument with a diameter of 50 to 100 microns, coupled with a laser unit, which is first installed in the proximal and then in the distal parts of anterior and middle cerebral arteries, where the laser treatment is carried out. The distal end of the fiber-optic instrument is constantly washed with heparinized saline solution. To carry out X-ray control, small doses of radiopaque substance are periodically introduced. The laser treatment is carried out using a low-energy laser of the visible spectrum of 20 milliwatt power, operating in either continuous or pulsed or combined modes. Exposure time is about 20 - 40 minutes. After the surgery the patient undergoes repeated cerebral multi-gated angiography by the procedure described above, the results of which determine the degree of revascularization and restoration of the microvasculature [44]. We assume that if the capillary blood flow is not fully restored during the first attempt of the intervention, the manipulation can be repeated, but during the endovascular interventions described it was not necessary.

In the Test Group, patients with a high risk of AD development or with AD pre-clinical stage (Group CDR-0) underwent the endovascular laser intervention, as described above, prophylactically, against the background of growing memory disorders. Patients suffering from AD (Groups CDR-1, CDR-2, and CDR-3) underwent the intervention in a period of 1 year to 12 years from the appearance of the initial disease symptoms.

Postoperative treatment was carried out by common interventional angiology schemes and dosing. The patients underwent conventional desagrigant, anticoagulant and vasodilator therapy including Aspirin, Heparin, and indirect anticoagulants (depending on the blood coagulation indicators), Pentoxifylline $100 \mathrm{mg}$, Complamin 150 $\mathrm{mg}$, Inosin $200 \mathrm{mg}$, Nootropil (Piracetam) $1200 \mathrm{mg}$ (or Gliatilin $1000 \mathrm{mg}$ ) intravenously, No. 10-15; and then they took tablets. Subsequent 3-months courses of tablets were repeated twice a year. The patients did not take any specific drugs aimed at the treatment of AD.

In the Control Group, the therapeutic treatment was conducted according to the conventional patterns and dosages [33,45-47]. Patients in Group CDR-0 received nootropic drugs: $2400 \mathrm{mg}$ per day of Nootropil (Piracetam) (3 - 4 months courses), or $1200 \mathrm{mg}$ per day of Gliatilin (4 - 6 months courses). Patients in groups CDR-1, CDR-2, and CDR-3 took 5 - $20 \mathrm{mg}$ per day of Memantin, as a neuroprotective drug, or 3 - $12 \mathrm{mg}$ per day of Rivastigmine, as a cholinergic drug. Simultaneously, patients of all groups were receiving vasoactive drugs: 3 -months courses 
of Pentoxifylline (800 mg per day) and of Complamin (450 $\mathrm{mg}$ per day) which were repeated twice a year.

Against the background of the conducted treatment, the patients underwent repeated REG every 6 months; $\mathrm{CT}$, MRI and SG of the brain every 12 months, and MUGA in $2-5$ years.

\section{Results}

\subsection{Test Group}

Neither the endovascular intervention nor the postoperative treatment caused any complications or deaths.

In Group CDR-0, postoperative cerebral MUGA showed restoration of capillary blood flow accompanied by reduction of arteriovenous shunts and improvement of venous return among all 4 patients (Figures 1(a)-(b)).

According to SG, 3 (75\%) patients had complete restoration of blood flow velocity in the cerebral hemispheres: Tmax-7.15 - $8.75 \mathrm{sec}, \mathrm{T} 1 \backslash 2-5$ - $7 \mathrm{sec}$; and $1(25 \%)$ patient had incomplete restoration of it: Tmax $-8.92 \mathrm{sec}$, T1 $\backslash 2-12.25 \mathrm{sec}$.

According to REG, 3 (75\%) patients had normalizetion of pulse blood flow in the carotid basin, and $1(25 \%)$ patient had reduction of pulse blood flow by 8 and $12 \%$.

Brain CT performed 12 months after the endovascular interventions showed that all 4 patients had an increase in the tissue mass of the temporal lobes of the brain of $2 \%$ $6 \%$ which was accompanied by a narrowing o Sylvius fissures and subarachnoid space in the fronto-parietal and temporal regions (Figures 2(a)-(b)).

Further on, this effect persisted throughout the whole observation period (over 6 years) (Figure 9).

According to cerebral postoperative MUGA, all 15 patients of Group CDR-1 had restored capillary blood flow accompanied by reduction of arteriovenous shunts and mprovement of venous return (Figures 3(a)-(b)).

According to SG, 13 (86.6\%) patients had complete restoration of blood flow velocity in the cerebral hemispheres: Tmax $-6.25-8.25 \mathrm{sec}$, T1 $12-5$ - $6 \mathrm{sec} ; 2$ (15.4\%) patients had incomplete restoration of it: Tmax $-8.72-9.25 \mathrm{sec}$., T1 $\backslash 2-9.15-12.0 \mathrm{sec}$.

According to REG, 14 (93.3\%) patients had normalization of pulse blood flow in the carotid basin, and 1 patient $(6.7 \%)$ had an increase in pulse blood flow of $6 \%$ above normal.

According to brain CT performed 12 months after the endovascular interventions, all 15 patients showed an increase in the tissue mass of the temporal lobes of the brain of $6 \%-10 \%$, which was also accompanied by narrowing of Sylvius fissures and subarachnoid space in the fronto-parietal and temporal regions. In 2 - 3 years a further increase in the tissue mass of the temporal lobes to the age norm was noted, accompanied by further narrowing of Sylvius fissures and subarachnoid space in the fron- toparietal and temporal regions (Figures 4(a)-(c)).

Further on, this effect persisted for the entire period of observation (Figure 9).

According to cerebral postoperative MUGA, all 20 patients of Group CDR-2 had restoration of capillary blood flow accompanied by reduction of arteriovenous shunts (Figures 5(a)-(b)).

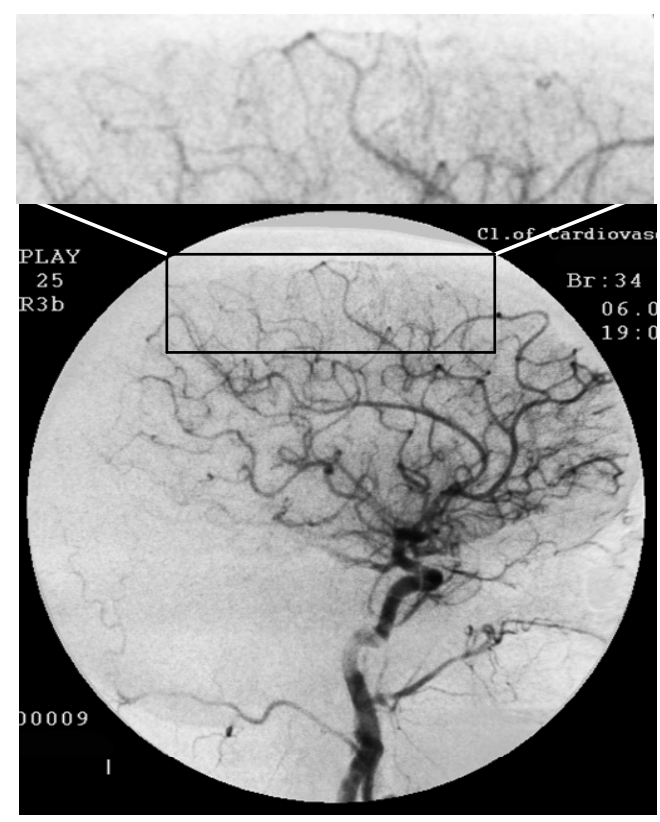

(a)

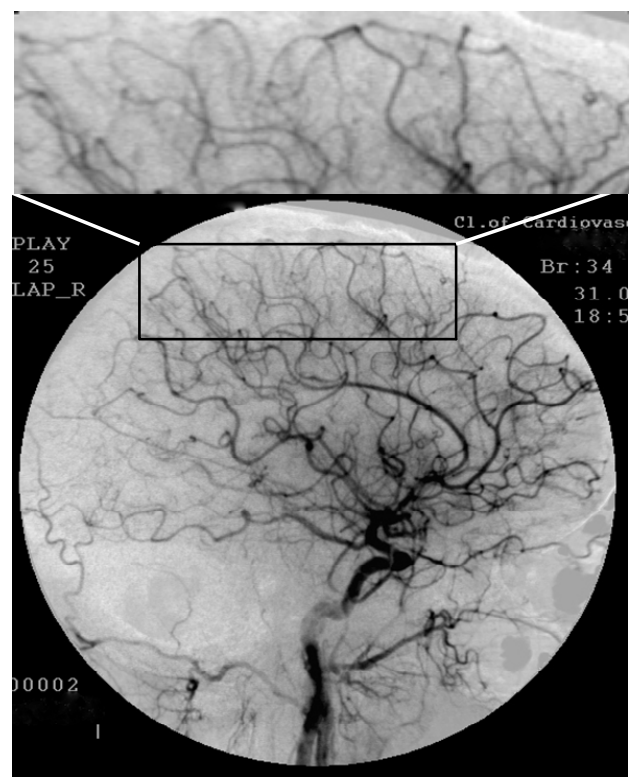

(b)

(a): 1) Hypovascular area in the fronto-parietal region. 2) Multiple arteriovenous shunts; (b): 1) Restoration of capillary blood flow in the temporal and fronto-parietal regions. 2) Reduction of arteriovenous shunts.

Figure 1. Patient P., 34, right internal carotid artery angiogram, side view, late arterial phase. (a) Prior to the endovascular treatment; (b) After the endovascular treatment. 


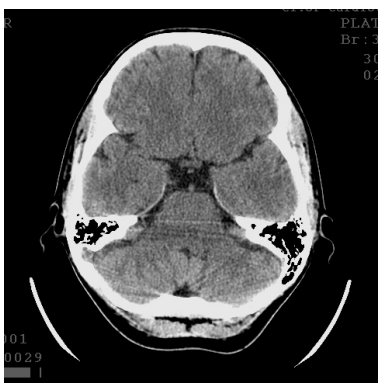

(a)

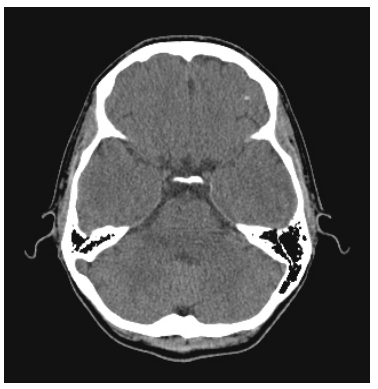

(b)

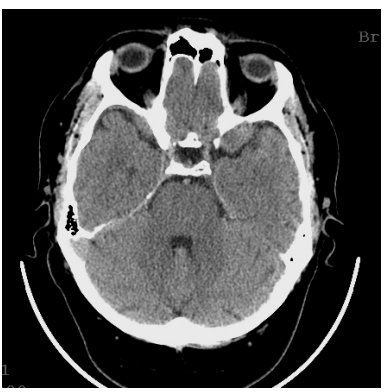

(a)

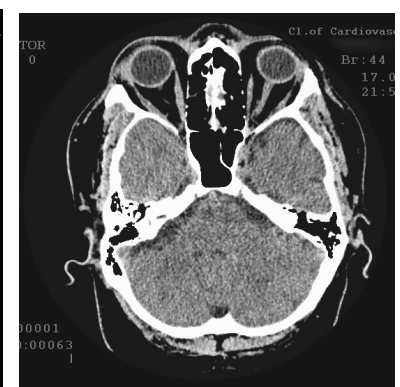

(b)

(a) Atrophy of the right temporal lobe 9\%, of the left one 7\%; (b) Reduction of the right temporal lobe atrophy to $4 \%$, of the left one to $3 \%$. Narrowing of Sylvius fissures

Figure 2. Patient P., 34, CT. (a) Prior to the endovascular treatment; (b) 12 months after the endovascular treatment.

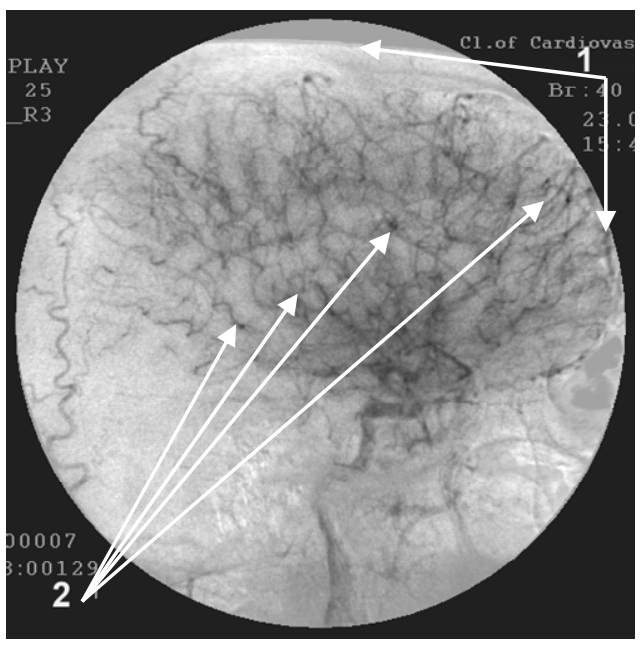

(a)

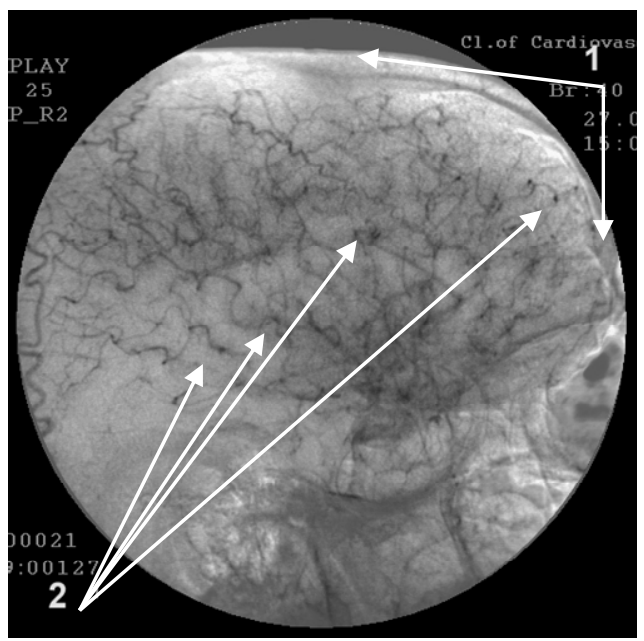

(b)

(a) 1) Reduction of capillary blood flow; 2) Multiple arteriovenous shunts in the temporal and fronto-parietal regions; (b) 1) Restoration of capillary blood flow; 2) Reduction of arteriovenous shunts.

Figure 3. Patient S., 40, right internal carotid artery angiogram, side view, capillary phase. (a) Prior to the endovascular treatment; (b) After the endovascular treatment.

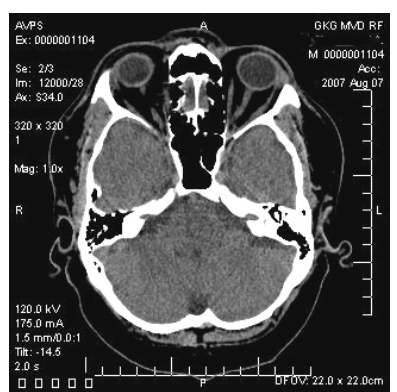

(c)

(a) Atrophy of the temporal lobes $18 \%$; (b) Reduction of the atrophy to $9 \%$; (c) Reduction of the atrophy to $5 \%$.

Figure 4. Patient S., 40, CT. (a) Prior to the endovascular treatment; (b) 12 months after the treatment; (c) 4 years after the treatment.

Improved venous return was observed among 17 (85.0\%) patients; partial preservation of venous congestion was observed among $3(15.0 \%)$ patients. Delayed angiographic studies performed at intervals of $2-6$ years after the endovascular treatment showed persistence of the restored collateral and capillary bed with the reduction of arteriovenous shunts as well as the signs of further strengthening of the capillary and collateral revascularization (Figure 5(c)).

According to SG, $16(80.0 \%)$ patients had restoration of blood flow velocity in the cerebral hemispheres: Tmax -6.50 - $8.50 \mathrm{sec}, \mathrm{T} 1 \backslash 2-6$ - $9 \mathrm{sec} ; 4(20.0 \%)$ patients had incomplete restoration of it: Tmax -9.0 - $9.5 \mathrm{sec}, \mathrm{T} 112-$ $11.5-12.5 \mathrm{sec}$.

According to REG, 15 (75.0\%) patients had normalization of pulse blood flow in the carotid basin; 5 patients $(25.0 \%)$ had reduction of pulse blood flow by $9 \%-12 \%$; $2(10.0 \%)$ patients showed an increase in pulse blood of $6 \%-8 \%$ above normal.

Brain CT performed 12 months after the endovascular interventions showed that all 20 patients had an increase in the tissue mass of the temporal lobes of the brain of $14 \%-15 \%$ which was also accompanied by narrowing of Sylvius fissures and subarachnoid space in the frontoparietal and temporal regions (Figures 6(a) and (b)).

Delayed CT-studies performed at intervals of $2-6$ years after the endovascular treatment showed a further increase in the tissue mass of the temporal lobes of the brain 
to the age norm, which was accompanied by further narrowing of Sylvius fissures and subarachnoid space in the fronto-parietal and temporal regions (Figures 6(c), 6(d) and 9).

According to cerebral postoperative MUGA, all 7 pa-

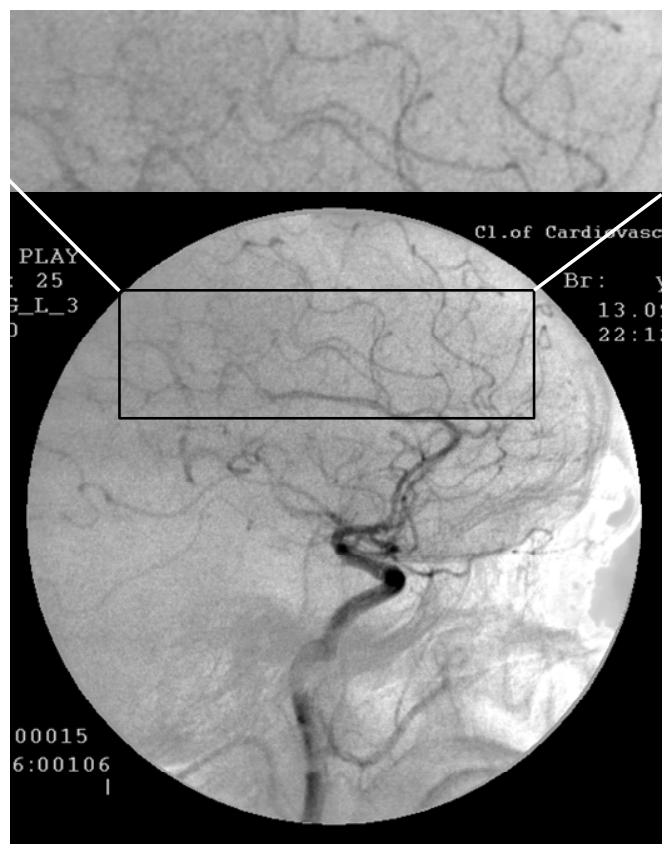

(a) tients of Group CDR-3 had restoration of capillary blood flow accompanied by reduction of arteriovenous shunts and improvement of venous return (Figures 7(a) and (b)).

According to SG, 4 (57.1\%) patients had restoration of blood flow velocity in the cerebral hemispheres: Tmax-

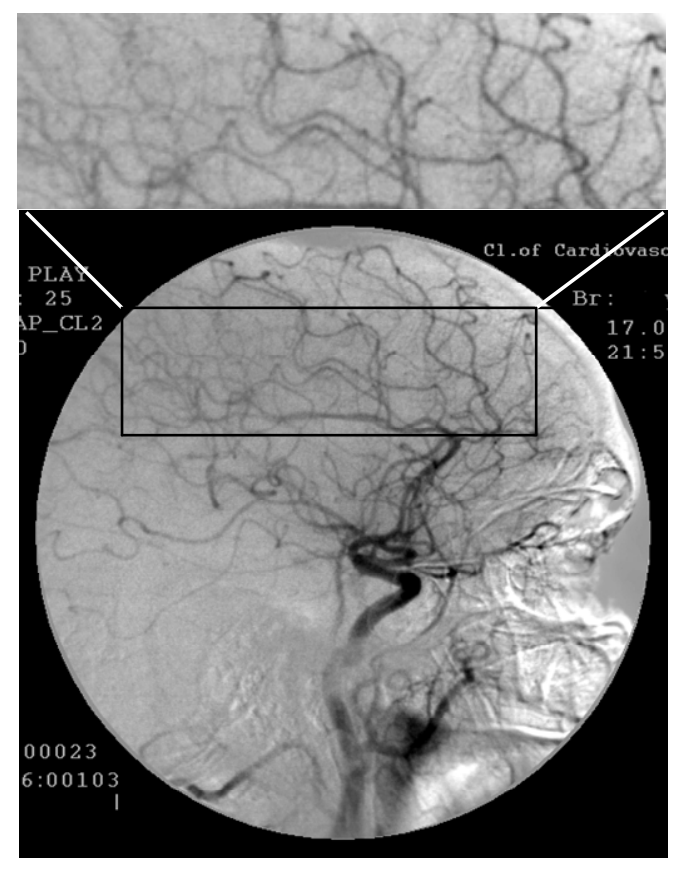

(b)

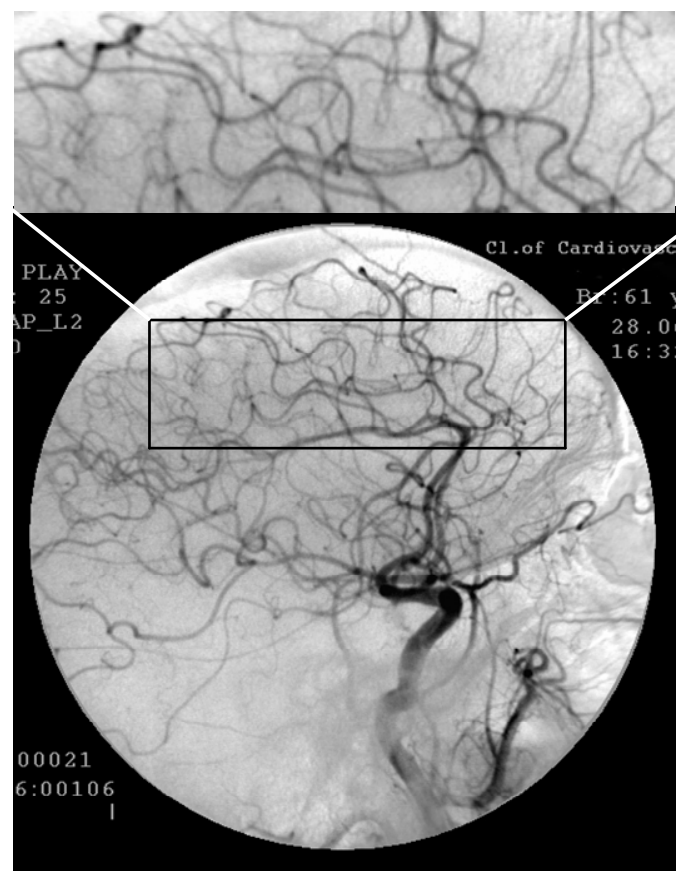

(c)

(a) Reduction of the capillary bed in the temporal and frontoparietal regions; (b) Restoration of the capillary and collateral channels; (c) Further improvement of the capillary and collateral channels.

Figure 5. Patient S., 57, left internal carotid artery angiogram, side view, arterial phase. (a) Prior to the endovascular treatment; (b) After the endovascular treatment; (c) 5 years after the endovascular treatment. 


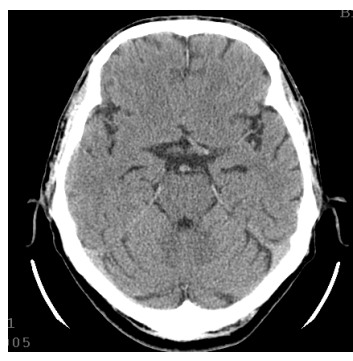

(a)

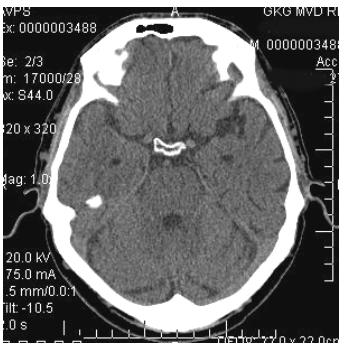

(c)

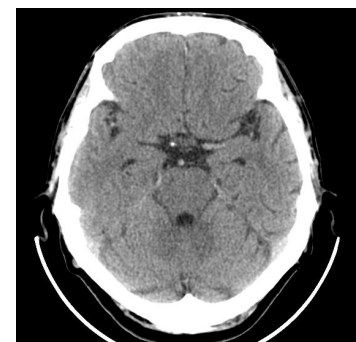

(b)

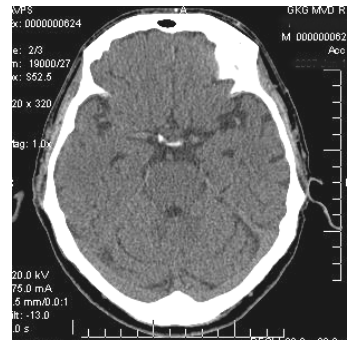

(d)
(a)Atrophy of the temporal lobes on the right $28 \%$, on the left $22 \%$; (b) Reduction of the atrophy: on the right $12 \%$, on the left $11 \%$; (c) Normalization of the temporal lobes tissue volume; (d) Normalization of the temporal lobes tissue volume.

Figure 6. Patient T., 57, CT. (a) Prior to the endovascular treatment; (b) 12 months after the treatment; (c) 2 years after the treatment; (d) 5 years after the treatment.

$7.25-8.50 \mathrm{sec}, \mathrm{T} 1 \backslash 2-7-10 \mathrm{sec} ; 4(42.9 \%)$ patients had incomplete recovery of it: Tmax-9.0 - $10.5 \mathrm{sec}, \mathrm{T} 1 \backslash 2$ 11.0 - $12.5 \mathrm{sec}$.

According to REG, 3 (42.9\%) patients had normalization of pulse blood flow in the carotid basin; and 4 $(57.1 \%)$ patients had an increase in pulse blood flow of $6 \%-11 \%$ above normal.

According to brain CT performed 6 - 12 months after the endovascular interventions, all 7 patients showed an increase in the tissue mass of the temporal lobes of the brain by $10 \%-12 \%$, which was also accompanied by narrowing of Sylvius fissures and subarachnoid space in the relevant regions of the brain (Figures 8(a)-(b)).

Delayed CT performed at intervals of 2 - 3 years revealed that the tendency of the temporal lobes tissue mass to increase was preserved; however, certain negative changes showed in a longer interval (Figure 9).

After the endovascular treatment all patients had clinically positive changes accompanied by a decrease in the level of dementia, memory improvement, decline in cognitive disorders, intellectual capacity improvement, the improvement of the condition of higher mental functions and of social adjustment; however, the degree of this effect and the period of its growth were not the same in different groups of patients.

Patients of Group CDR-0 had basically had fairly poor symptoms manifested in progressive deterioration of memory, difficulties in remembering, distraction, and sometimes complications in communication. After the treat-

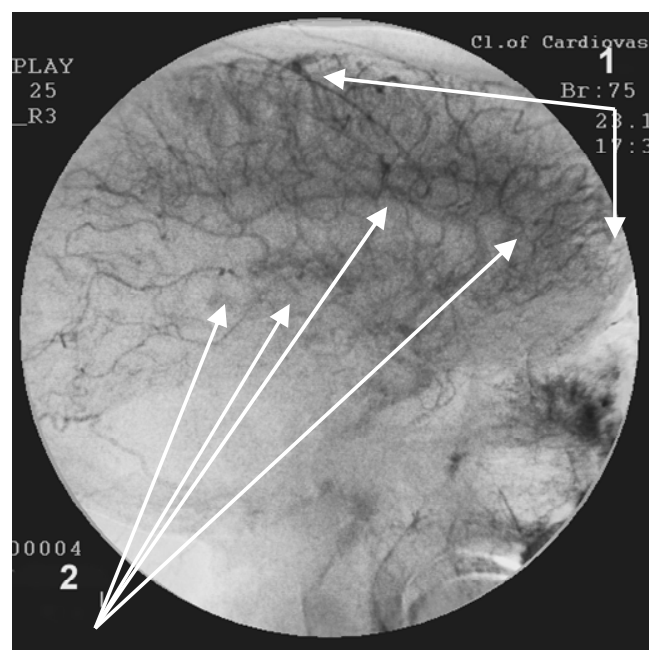

(a)

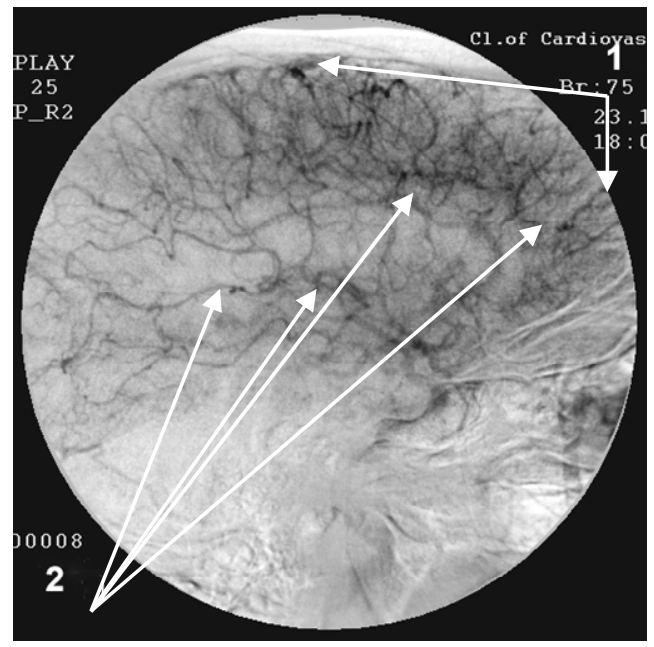

(b)

(a) 1) Reduction of capillary blood flow; 2) Multiple arteriovenous shunts in the temporal and fronto-parietal regions; (b) 1) Restoration of capillary blood flow; 2) Reduction of arteriovenous shunts.

Figure 7. Patient $P$., 57, right internal carotid artery angiogram, side view, capillary phase; (a) Prior to the endovascular treatment; (b) After the endovascular treatment.

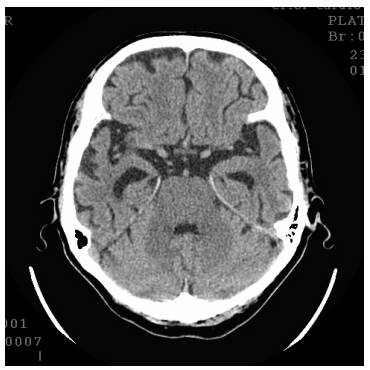

(a)

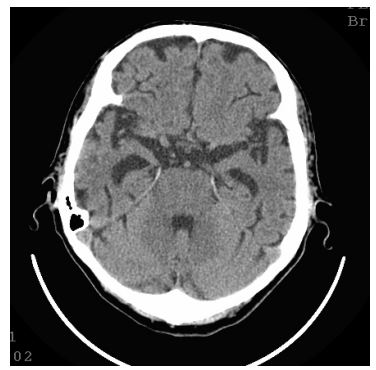

(b) (a) Atrophy of the temporal lobes $40 \%$; (b) Reduction of the atrophy on the right $12 \%$.

Figure 8. Patient P., 75, CT. (a) Prior to the treatment; (b) 6 months after the treatment. 


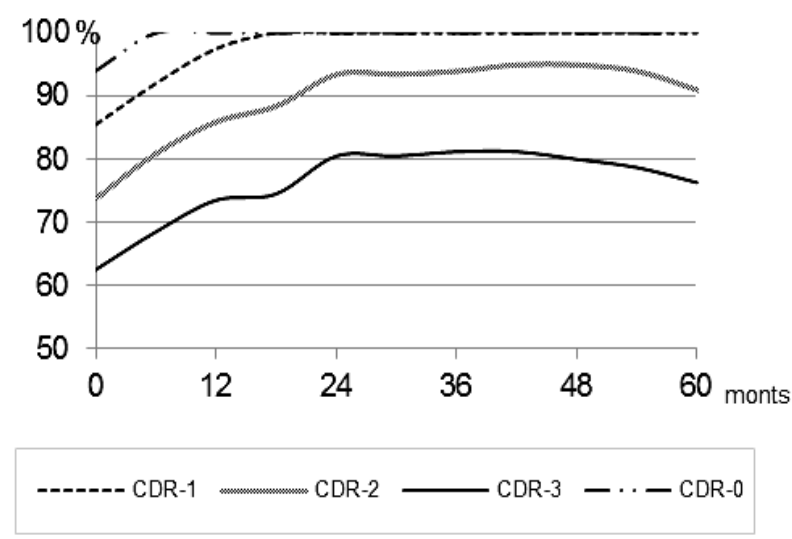

Figure 9. Changes in the volume of the temporal lobes of the brain among Test Group patients.

ment, these symptoms completely disappeared in $2-4$ months. According to MMSE results, the maximum positive effect ( 28 - 30 points) was observed in $6-12$ months, and the patients treated completely restored to health for the whole observation period.

Patients of Group CDR-1 showed a more pronounced positive reaction in the early postoperative period. The ability to memorize improved in the first days, cognitive disorders regressed; in a month the patients returned to their work and practically did not differ from other healthy people in any way. Over the next year the positive trend continued to progress and was accompanied by full restoration of the ability to remember, the restoration of higher mental functions; the patients showed an inclination to learn foreign languages, had restored introspecttion, intellectual ability; cognitive impairments completely disappeared. When MMSE results showed the positive effect (27 - 28 points) in $8-14$ months, the patients were switched to Group CDR-0, and then, having achieved 28 - 30 points, were considered as healthy individuals, the positive trend continuing for the whole observation period.

Patients of Group CDR-2 showed an even more pronounced positive reaction in the early postoperative period. All these patients had suffered from sufficiently severe cognitive impairments, had had pronounced deterioration of immediate and delayed memory, of the process of introspection and intelligence, had had permanent disorientation and behavioral disorders. Literally in 1 or 2 days after the endovascular treatment, the patients remembered and analyzed the shortcomings of their behavior in the preoperative period and apologized for them.

The patients became more sociable and talkative, they had their higher mental functions restored, their mental stress tolerance increased; there appeared a need to actively analyze what was happening around them. Of the 6 who had worked for two years before the treatment, 5 $(83.3 \%)$ successfully returned to the previously performed intellectual work within $2-4$ months after the treat- ment. MMSE results showed the maximum positive effect (23 - 25 points) in $8-18$ months, and the patients were switched to Group CDR-1; further on the positive effect persisted for 3 - 4 years; and then there was a certain decline to $20-21$ points.

Patients of Group CDR-3 had slower recovery process. However, in 2 or 3 weeks they became more sociable and talkative; their cognitive impairments and disorientation diminished; they began to read, write, to reason logically, to recognize their relatives and the staff of the clinic. The patients' behavior became more adequate, and communication with them much easier. A few months later the patients often did not require constant supervision and nursing care, and could care for themselves. MMSE results showed the maximum positive effect (17 - 19 points) in $12-18$ months, and the patients were switched to Group CDR-2. The positive effect lasted for about 24-30 months; then it decreased to $12-13$ points.

\subsection{Control Group}

In Group CDR-0, according to SG and REG data, there were no significant changes against the background of the treatment.

According to brain CT performed 24 months after the beginning of the treatment, $1(20 \%)$ patient had no reduction of the tissue mass of the temporal lobes. $2(40.0 \%)$ patients had a tendency of the tissue mass to reduce. Other $2(40.0 \%)$ patients had growing atrophic changes of the temporal lobes, with a decrease in tissue mass of 14\% - 18\% (Figures 10(a)-(b)).

Further on, in a period of observation of 5 - 6 years, a tendency towards the tissue mass reduction remained (Figure 11).

In Group CDR-1, according to SG and REG, there were no significant changes against the background of the treatment; and the data remained virtually the same in spite of periodic fluctuations. According to brain CT performed 12 - 36 months after the beginning of the

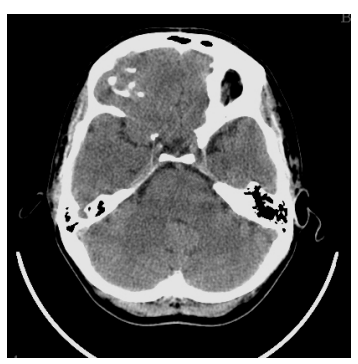

(a)

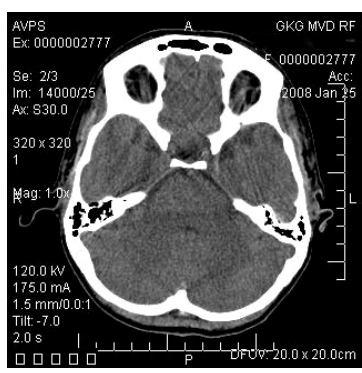

(b) (a) Total atrophy of the temporal lobes $8 \%$; (b) Increase in the atrophy up to $18 \%$.

Figure 10. Patient P., 35, CT. (a) Prior to the conservative treatment; (b) 2 years after the beginning of the conservative treatment. 


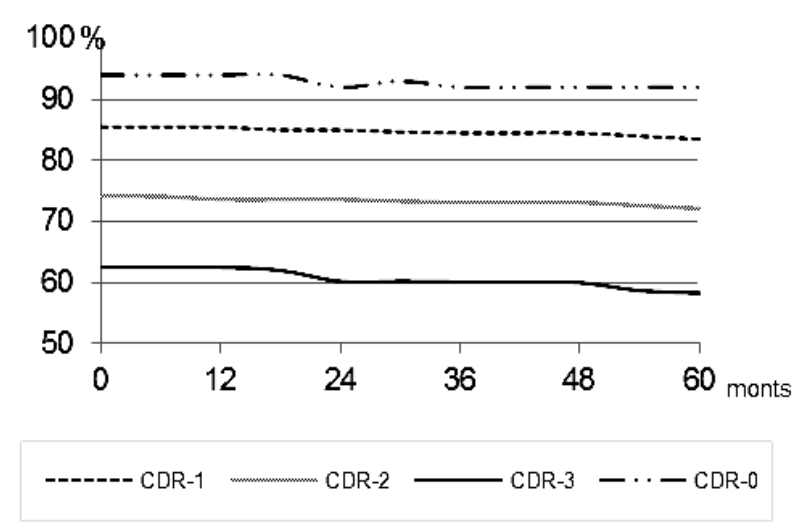

Figure 11. Changes in the volume of the temporal lobes of the brain among Control Group patients.

conservative treatment, all patients showed a tendency towards the growth of atrophic changes in the temporal lobes of the brain with a decrease in the tissue mass of $5 \%-7 \%$. During further period of observation the tendency of the tissue mass to decrease remained (Figure 11).

In Group CDR-2, according to SG and REG data, 7 (63.6\%) patients showed deterioration of cerebral blood flow velocity and pulsatile blood flow, and 4 (36.4\%) patients had no pronounced changes against the background of the treatment. According to brain CT performed $12-36$ months after the beginning of the treatment, $5(45.5 \%)$ patients had a tendency towards the reduction of the tissue mass of the temporal lobes of the brain. $6(54.5 \%)$ patients had growing atrophic changes of the temporal lobes, with a decrease in the tissue mass of $5 \%-9 \%$. During further period of observation the tendency towards the tissue mass decrease remained (Figure 11).

In Group CDR-3, according to SG and REG data against the background of the conventional treatment, 3 $(30.0 \%)$ patients showed improvement of cerebral blood flow velocity and pulsatile blood flow that may be associated with an increase of blood flow due to arteriovenous shunts. 7 (70.0\%) patients did not have any significant changes. According to brain CT performed 12 - 24 months after the beginning of the conservative treatment, all 10 patients had an increase in the atrophic changes in the temporal lobes of the brain, and a decrease in the tissue mass of 5\% - 14\% (Figures 12(a)-(b)).

During further period of observation the tendency of the tissue mass to decrease could be observed (Figure 11).

Clinically positive changes after the beginning of the treatment were manifested in the temporary stabilization of the initial state of some groups of patients for certain, sometimes sufficiently long periods of time. In the first 6 months after the beginning of the conservative treatment there was a slight improvement in the patients' selfawareness, the communication with them became easier,

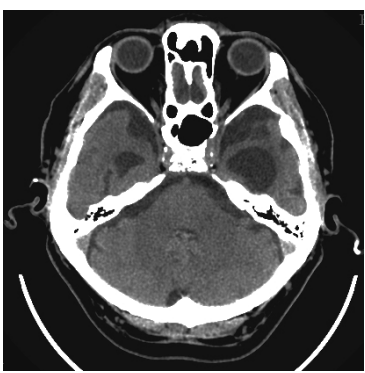

(a)

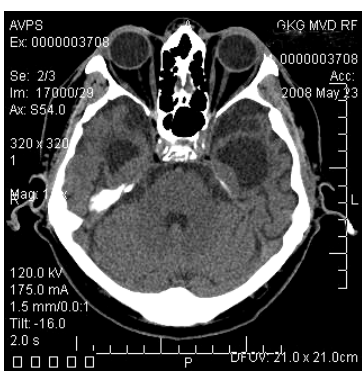

(b) (a) Total atrophy of the temporal lobes $58 \%$; (b) Increase in the atrophy up to $64 \%$

Figure 12. Patient S., 67, CT. (a) Prior to the conservative treatment; (b) 2 years after the beginning of the conservative treatment.

there was a certain decrease in cognitive impairments and a partial improvement in intellectual abilities.

According to MMSE results in Group CDR-0, the maximum positive effect ( $27-28$ points) was observed 6 months after the beginning of the treatment, and then it gradually decreased to $24-25$ points during the entire observation period.

In Group CDR-1 the maximum positive effect (23 points) was observed 6 months after the beginning of the treatment, further on it was stabilized for 2 and even 3 years, and then there developed a tendency towards a decrease (20 - 21 point).

In Group CDR-2 the maximum positive effect (16 points) was observed in $6-12$ months after the beginning of the treatment. The effect lasted for about 1 year and then there was a decline to $11-12$ points.

In Group CDR-3 the maximum positive effect ( 9 points) was observed 6 months after the beginning of the treatment, and further on there was a rapid decline to 6 7 points.

MMSE results before and after the treatment are statistically and qualitatively different in the Test and Control Groups. Against the background of the treatment in the Test Group, there is an increase in the number of received points and the patients are transferred to an earlier CDR-group. In the Control Group, such tendency is not observed and the changes in cognitive disorders and higher mental functions occur within the same CDRgroup. This is statistically confirmed by an analysis of contingency tables with the chi-square test. Prior to the beginning of the therapy there were no significant differences between the Test and Control Groups (Chisquare value equal to $3.31, \mathrm{p}=0.35$ ). Against the background of the therapy the differences reach statistical significance (Chi- square value is $34.25, \mathrm{p}<0.001$ ). It is also confirmed by Mann-Whitney test (Table 1) for intergroup comparison. Simultaneously, there are statistically significant (according to the sign test) differences between the results at the beginning and at the end of the 
Table 1. Comparison of the Test and Control Groups by Mann-Whitney test at the beginning and the end of the therapy.

\begin{tabular}{|c|c|c|c|c|c|c|c|c|c|c|}
\hline & \multicolumn{10}{|c|}{ Mann-Whitney U Test (Data. sta) } \\
\hline & \multicolumn{10}{|c|}{ By variable group } \\
\hline & \multicolumn{10}{|c|}{ Marked tests are significant at $\mathrm{p}<0.05000$} \\
\hline variable & $\begin{array}{l}\text { Rank Sum } \\
\text { Test group }\end{array}$ & $\begin{array}{l}\text { Rank Sum } \\
\text { Control } \\
\text { group }\end{array}$ & $\mathrm{U}$ & Z & p-level & $\mathrm{Z}$ adjusted & p-level & $\begin{array}{l}\text { Valid N Test } \\
\text { group }\end{array}$ & $\begin{array}{l}\text { Valid N } \\
\text { Control } \\
\text { group }\end{array}$ & $\begin{array}{l}2 * 1 \text { sided } \\
\text { exact } \mathrm{p}\end{array}$ \\
\hline $\begin{array}{c}\text { score before } \\
\text { treatment }\end{array}$ & 1979.5 & 1341.5 & 711.5 & 0.891 & 0.373 & 0.895 & 0.371 & 46 & 35 & 0.375 \\
\hline $\begin{array}{c}\text { score after } \\
\text { treatment }\end{array}$ & 2485.5 & 835.5 & 205.5 & 5.716 & 0.000 & 5.739 & 0.000 & 46 & 35 & 0.000 \\
\hline
\end{tabular}

treatment $(Z=6.63, \mathrm{p}<0.001)$ within the Test Group, while in the Control Group no significant differences at the beginning and at the end of the therapy have been found $(\mathrm{Z}=1.48, \mathrm{p}=0.14)$.

\section{Discussion}

According to many authors, the treatment of AD should ideally begin in the preclinical stage of the disease when only an insignificant number of neurons are damaged [8]. This issue has received considerable attention at AAIC 2011.

Regardless of the stage, the vascular factor manifested in DAAT [44] plays an important role in the development of AD [22-26]. The treatment of AD should focus not only on the normalization of metabolic processes in the brain tissue, the stabilization of neurons, the destructtion or removal of abnormal amyloid, but also on the restoration of the vascular bed. The concept of discirculatory angiopathy of Alzheimer's type (DAAT) is wider than F. Morel's concept of drusoidal angiopathy [21], because certain disorders are observed both in the arteriary, capillary and venous beds, and not only in the capillaries [25,27]. The intensity of these disorders does not depend on the severity of dementia, the manifestations of cognitive disorders, or on the timing of AD development. It is not possible to state with certainty that the vascular disorders are associated with the early deposition of amyloid in the capillary or arterial wall [34]. Moreover, it is unlikely that such amyloid deposition occurs long before the symptoms appear. As a result, the question of what is primary arises: if certain innate or somehow acquired disorders of blood supply and microcirculation of the brain contribute to the development of $\mathrm{AD}$ [25], or if the disease itself causes similar changes in the distal arterial, microcirculatory and venous bed $[35,36]$.

The severity of the disease, of dementia and of cognitive impairments, and the state of higher mental functions often directly depend on the severity of atrophic changes in the brain tissue [9-12]. Thus, atrophic changes of the temporal lobes were $4 \%-8 \%$ among patients with preclinical stage (CDR-0), but the degree of atrophy in- creased to $33 \%$ - $64 \%$ among patients with late-stage AD (CDR-3) [12,16,35], though vascular disorders that occur in the brain during the development of $\mathrm{AD}$ are at about the same level among all patients regardless of their CDR Group [22-24,35].

The brain tissue has a low degree of absorption of laser energy of the visible spectrum, and therefore the depth of its penetration is several centimeters [48]. As a result, laser action has an impact not only on the vascular wall causing the recovery of the capillary and collateral bed $[34,42,43,48]$, but also on the brain tissue containing the abnormal amyloid. It is likely that laser energy transfer not only stimulates metabolic processes in functioning neurons [25,34,48,49], but also simultaneously inhibits or hinders the process of the growth of the number of abnormal amyloids in the brain tissue. It is possible that subsequent quite rapid recovery of the tissue mass of the temporal and fronto-parietal lobes of the brain implies the development of some regenerative changes in the cerebral tissue [48-51]. This hypothesis is indirectly confirmed by increasingly emerging experimental studies which prove the possibility of regenerative processes in the brain tissue [52].

In the Test Group a positive effect after the treatment was observed among all patients, which means that endovascular treatment method is a highly promising one; however, the intensity of this effect in different groups of patients is manifested differently. It depends on the degree of the brain tissue involvement during the development of AD and, obviously, on the ability of the tissue for restorative and regenerative processes. In groups CDR-0 and CDR-1 a relatively small number of neurons was affected [8], and the treatment has led to a sufficiently rapid and persistent positive outcome of the functional recovery of the brain for the entire period of observation. In the future the positive effect is likely to persist for many years. In groups CDR-2 and CDR-3 the tissue was affected to a much greater extent, but in spite of it the endovascular treatment resulted in a sufficiently rapid positive effect, although the number of the affected neurons has not allowed restoring the damaged brain functions to a greater extent. Nevertheless, the treatment has 
improved the patients' condition, reduced the level of dementia and cognitive impairment, and has made it possible to transfer the patients to CDR-groups of earlier stages, which is a sign of improving their standard of living.

In the Control Group the treatment was carried out according to common therapeutic schemes with application of nootropic, neuroprotective and cholinergic drugs; the patients additionally underwent vasoactive therapy similar to the one obtained by the Test Group patients after the endovascular treatment. The treatment was primarily aimed at improving and stabilizing the metabolic processes in the brain tissue and at improving the blood circulation. As a result, the positive effect has also been received and it also depended on the stage of the disease and the degree of the brain tissue involvement. The essence of this effect was not in the reduction of the level of dementia and cognitive impairments, but in the temporary stabilization of the patients' condition and their standard of living which had been observed before the beginning of the treatment.

In Group CDR-0, the patients' initial state stabilized for a period of 2 or 3 years and was followed by deterioration accompanied by worse MMSE results, and, in some cases, by the development of sufficiently pronounced $(18 \%)$ atrophic changes in the tissue of the temporal lobes of the brain.

In Group CDR-1 the patients' initial state also stabilized for a period of 2 or 3 years, but then the negative changes also appeared accompanied by growing atrophic changes in the temporal lobes tissue and worse MMSE results.

In groups CDR-2 and CDR-3 comprised of patients with sufficiently large areas of affected brain tissue, a stabilization effect has also taken place, but its time was relatively short. The negative trend was rapidly increaseing, accompanied by growing atrophic changes in the tissue of the temporal lobes and the exacerbation of dementia and cognitive impairment. The data obtained in this group of patients treated correlates with the data obtained by other authors [33,45-47].

\section{Conclusions}

Thus, the endovascular method can be named an effecttive one in the treatment of discirculatory angiopathy of Alzheimer's type (DAAT), which in its turn has a positive effect in treating AD. It is not traumatic as it has not resulted in any complications or deaths even among severely affected patients. Consequently, the implementation of endovascular intervention has sufficiently low risk. The effectiveness of the proposed treatment at all stages of the disease is much higher than the one of the conservative treatment carried out among the Control Group patients.

We do not make final conclusions. However, giving endovascular treatment to patients with preclinical AD (CDR-0) or to patients with early-stage AD (CDR-1) may prevent further disease progression.

Carrying out this treatment among patients with more severe dementia, persistent cognitive impairment and more advanced stages of AD (CDR-2, CDR-3) allows slowing down or halting further disease progression and may cause its regression. Group CDR-2 patients go back to society and in some cases even to the work previously performed, which leads them to rather full and comfortable life. Communication with patients from group CDR3 becomes much easier; they become able to care for themselves, which consequently brings significant relief to their relatives and friends.

Carrying out conventional therapeutic treatment among patients with $\mathrm{AD}$ using nootropics, neuroprotective and cholinergic drugs in combination with vasoactive therapy does not lead to the regression of AD symptoms but only leads to temporary stabilization of the initial condition of the patients.

\section{REFERENCES}

[1] Alzheimer's Disease Facts and Figures, 2007. A Statistical Abstract of US Data on Alzheimer's Disease published by the Alzheimer's Association. http://www.alz.org/national/documents/Report 2007Facts AndFigures.pdf

[2] Alzheimer's Disease Facts and Figures, Alzheimer's Association, 2010.

http://www.alz.org/documents_custom/report_alzfactsfig ures2010.pdf

[3] Generation Alzheimer's: The Defining Disease of the Baby Boomers.

http://act.alz.org/site/DocServer/ALZBoomersReport.pdf ?docID $=521$

[4] Alzheimer's Disease Facts and Figures, 2011. http://www.alz.org/downloads/Facts Figures 2011.pdf

[5] R. Altman and J. C. Rutledge, "The Vascular Contribution to Alzheimer's Disease," Clinical Science, Vol. 119, 2010, pp. 407-421. doi:10.1042/CS20100094 http://www.ncbi.nlm.nih.gov/pmc/articles/PMC2950620/ ?tool=pubmed

[6] R. A. Sperling, P. S. Aisen, L. A. Beckett, et al., "Toward Defining the Preclinical Stages of Alzheimer's Disease: Recommendations from the National Institute on Aging-Alzheimer's Association Workgroups on Diagnostic Guidelines for Alzheimer's Disease," Journal of Alzheimer's \& Dementia, Vol. 7, No. 3, 2011, pp. 280-292. http://www.alzheimersanddementia.com/article/S1552-52 60(11)00099-9/abstract

[7] A. Fagan, C. Xiong, R. Bateman, et al., "Plasma and Cerebrospinal Fluid Markers in the DIAN Study of Autosomal-Dominant Alzheimer's Disease," Journal of Alzheimer's \& Dementia, Vol. 7, No. 4, 2011, p. 287. http://www.alzheimersanddementia.com/article/S1552-52 $\underline{60(11) 00972-1 / \text { fulltext }}$ 
[8] R. J. Perrin, R. Craig-Schapiro, J. C. Morris, et al., "Identification and Validation of Novelcerebrospinal Fluid Biomarkers for Staging Early Alzheimer's Disease," Public Library of Science One, Vol. 12, No. 6, 2011, p. e16032.

http://www.ncbi.nlm.nih.gov/pmc/articles/PMC3020224/ ?tool=pmcentrez

[9] B. C. Dickerson, "Functional Magnetic Resonance Imaging of Cholinergic Modulation in Mild Cognitive Impairment," Current Opinion in Psychiatry, Vol. 19, 2006, pp. 299-306. doi:10.1097/01.yco.0000218602.25346.c6 http://www.nmr.mgh.harvard.edu/ bradd/dickerson curro pnpsych 2006.pdf

[10] A. J. Saykin, H. A. Wishart, L. A. Rabin, et al., "Older Adults with Cognitive Complaints Show Brain Atrophy Similar to That of Amnestic MCI," Neurology, Vol. 67, 2006, pp. 834-842. doi:10.1212/01.wnl.0000234032.77541.a2 http://www.neurology.org/cgi/content/abstract/67/5/834

[11] W. S. Tae, S. S Kim, K. U. Lee, et al., "Validation of Hippocampal Volumes Measured Usinga a Manual Method and Two Automated Methods (Free Surfer and IBASPM) in Chronic Major Depressive Disorder," Neuroradiology, Vol. 50, 2008, pp. 569-581. doi:10.1007/s00234-008-0383-9 http://www.ncbi.nlm.nih.gov/pubmed/18414838

[12] I. V. Maksimovich, L. N. Gotman and S. M. Masyuk, "Method of Determining Dimensions of Temporal Brain Lobes in Patients Suffering from Alzheimer's Disease," Russian Patent, No 2306102, 2006.

http://worldwide.espacenet.com/publicationDetails/biblio ?DB=EPODOC\&adjacent $=$ true \&locale $=$ en $E P \& F T=D \&$ date $=20070920 \& C C=\mathrm{RU} \& N R=2306102 \mathrm{C} 1 \& \mathrm{KC}=\mathrm{C} 1$

[13] S. L. Risacher, A. J. Saykin, J. D. West, et al., "Baseline MRI Predictors of Conversion from MCI to Probable AD in the ADNI Cohort," Current Alzheimer Research, Vol. 6, No. 4, 2009, pp. 347-361. doi:10.2174/156720509788929273 http://www.bentham.org/car/openaccssearticles/car6-4/00 07.pdf

[14] L. Shen, H. A. Firpi, A. J. Saykin, et al., "Parametric Surface Modeling and Registration for Comparison of Manual and Automated Segmentation of the Hippocampus," Hippocampus, Vol. 19, No. 6, 2009, pp. 588-595. doi:10.1002/hipo.20613 http://picsl.upenn.edu/caph08/papers/paper07.pdf

[15] G. Waldemar, B. Dubois, M. Emre, et al., "Recommendations for the Diagnosis and Management of Alzheimer's Disease and Other Disorders Associated with Dementia: EFNS Guideline," European Journal of Neurology, Vol. 14, No. 1, 2007, pp. e1-e26. doi:10.1111/j.1468-1331.2006.01605.x http://www.ncbi.nlm.nih.gov/pubmed/17222085

[16] I. V. Maksimovich, "Possibilities of Modern Computed Tomography of Brain in Alzheimer's Disease Diagnosis," The Neurologic Bulletin, Vol. XLI, No. 1, 2009, pp. 5-10. http://www.infamed.com/nb/1_2009_5-10.pdf

[17] S. Adriaase, E. Sanz-Arigita, M. Binnewijzend, et al., "Molecular Markers of Alzheimer's Disease Pathology and Their Relationship with Default Mode Network In- tegrity," Alzheimer's \& Dementia, Vol. 7, No. 4, 2011, pp. S2-S3. doi:10.1016/j.jalz.2011.05.005

http://www.alzheimersanddementia.com/article/S1552-52 60(11)00144-0/fulltext

[18] C. Jack, P. Vemuri, H. Viste, et al., "Ordering of Alzheimer's Disease Biomarkers," Alzheimer's \& Dementia, Vol. 7, No. 4, 2011, pp. S4-S5. doi:10.1016/j.jalz.2011.05.011

http://www.alzheimersanddementia.com/article/S1552-52 60(11)00150-6/images

[19] J. Q. Trojanowski, H. Vandeerstichele, M. Korecka, et al., "Update on the Biomarker Core of the Alzheimer's Disease Neuroimaging Initiative Subjects," Alzheimer's \& Dementia, Vol. 6, No. 3, 2010, pp. 230-238. doi:10.1016/j.jalz.2010.03.008 http://www.ncbi.nlm.nih.gov/pubmed/20451871

[20] P. T. Meyer, S. Hellwig, F. Amtage, et al., "Dual-Biomarker Imaging of Regional Cerebral Amyloid Load and Neuronal Activity in Dementia with PET and 11C- Labeled Pittsburgh Compound B," Journal of Nuclear Medicine, Vol. 52, No. 3, 2011, pp. 393-400. doi:10.2967/jnumed.110.083683 http://www.ncbi.nlm.nih.gov/pubmed/21321269

[21] F. Morel "An Apparently Dyshoric and Topical Angiopathy," Monatsschrift für Psychiatrie und Neurologie, Vol. 120, No. 5-6, 1950, pp. 352-357.

doi: $10.1159 / 000140150$ http://www.ncbi.nlm.nih.gov/pubmed/14806299

[22] I. Skoog, R. N. Kalaria and M. M. Breteler, "Vascular Factors and Alzheimer Disease," Alzheimer Disease and Associated Disorders, Vol. 13, No. 3, 1999, pp. 106-114. doi:10.1097/00002093-199912003-00016 http://www.ncbi.nlm.nih.gov/pubmed?term $=$ Skoog\%20I \%2C\%20Kalaria $\% 20 \mathrm{R} \% 20 \mathrm{~N} \% 2 \mathrm{C} \% 20$ Breteler $\% 20 \mathrm{M} . \mathrm{M}$.

[23] R. N. Kalaria, "Small Vessel Disease and Alzheimer's Dementia: Pathological Considerations," Cerebrovascular Diseases, Vol. 13 No. 2, 2002, pp. 48-52. doi:10.1159/000049150 http://www.ncbi.nlm.nih.gov/pubmed/11901243

[24] R. N. Kalaria, "Vascular Factors in Alzheimer's Disease," International Psychogeriatric, Vol. 15, No. 1, 2003, pp. 47-52. doi:10.1017/S1041610203008950 http://www.ncbi.nlm.nih.gov/pubmed/16191216

[25] I. V. Maksimovich, "Changes in Angioarchetectonics of Brain at Alzheimer's Disease," The Neurological Bulletin, Vol. XLI, No. 2, 2009, pp. 9-14. http://www.infamed.com/nb/2_2009_9-14.pdf

[26] P. A. Yates, R. Sirisriro, V. L. Villemagne, et al., "Cerebral Microhemorrhage and Brain \{beta\}-amyloid in Aging and Alzheimer's Disease," Neurology, Vol. 77, No. 1, 2011, pp. 48-54.

doi:10.1212/WNL.0b013e318221ad36

http://www.ncbi.nlm.nih.gov/pubmed/21700585

[27] I. V. Maksimovich, "Radiodiagnostics of Alzheimer's disease," Diagnostics and Intervention Radiology, Vol. 2, No. 4, 2008, pp. 27-38.

http://www.radiology-di.ru/articles/155/126/tom-2-N4-20 08.html

[28] G. Rodriguez, P. Vitali, P. Calvini, C. Bordoni, N. Girtler, 
G. Taddei, G. Mariani and F. Nobili, "Hippocampal Perfusion in Mild Alzheimer's Disease," Psychiatry Research, Vol. 100, No. 2, 2000, pp. 65-74.

doi:10.1016/S0925-4927(00)00071-8

http://www.ncbi.nlm.nih.gov/pubmed/11114492

[29] W. Chen, X. Song, S. Beyea, R. D'Arcy, Y. Zhan and K. Rockwood, "Advances in Perfusion Magnetic Resonance Imaging in Alzheimer's Disease," Journal of Alzheimer's \& Dementia, Vol. 7, No. 2, 2011, pp. 185-196. http://www.alzheimersanddementia.com/article/S1552-52 $\underline{60(10) 00105-6 / \text { abstract }}$

[30] R. O. Weller, M. Subash, S. D. Preston, I. Mazanti and R. O. Carare, "Perivascular Drainage of Amyloid-beta Peptides from the Brain and Its Failure in Cerebral Amyloid Angiopathy and Alzheimer's Disease," Brain Pathology, Vol. 18, No. 2, 2008, pp. 253-266. doi:10.1111/j.1750-3639.2008.00133.x http://www.ncbi.nlm.nih.gov/pubmed/18363936

[31] A. Pezzini, E. Del Zotto, I. Volonghi, A. Giossi, P. Costa and A. Padovani, "Cerebral Amyloid Angiopathy: A Common Cause of Cerebral Hemorrhage," Current Medicinal Chemistry, Vol. 16, No. 20, 2009, pp. 2498-2513. doi:10.2174/092986709788682047 http://www.ncbi.nlm.nih.gov/pubmed/19601795

[32] Y. A. Chung, O. J. Hyun, J. Y. Kim, K. J. Kim and K. J. Ahn, "Hypoperfusion and Ischemia in Cerebral Amyloid Angiopathy Documented by $99 \mathrm{mTc}-\mathrm{ECD}$ Brain Perfusion SPECT," Journal of Nuclear Medicine, Vol. 50, No. 12, 2009, pp. 1969-1974. doi:10.2967/jnumed.109.062315 http://www.ncbi.nlm.nih.gov/pubmed/19910418

[33] R. O. Weller, S. D. Preston, M. Subash and R. O. Carare, "Cerebral Amyloid Angiopathy in the Aetiology and Immunotherapy of Alzheimer's Disease," Alzheimer's Research \& Therapy, Vol. 1, No. 2, 2009, pp. 6-13. http://www.ncbi.nlm.nih.gov/pubmed/19822028

[34] I. V. Maksimovich and L. N. Gotman, "Method of Complex Radiation Diagnostics at Pre-clinical and Clinical Stages of Alzheimer's Disease," Russian Patent, No. 2315559, 2006. http://bankpatentov.ru/node/28577

[35] I. V. Maksimovich, "Dyscirculatory Angiopathy of the Brain of Alzheimer's Type," Journal of Alzheimer's \& Dementia, Vol. 6, No. 4, 2010, pp. e34-e35. http://www.alzheimersanddementia.com/article/S1552-52 60(10)02300-9/fulltext

[36] I. V. Maksimovich, "Dyscirculatory Angiopathy of A1zheimer's Type," Journal of Behavioral and Brain Science, Vol. 1, No. 2, 2011, pp. 57-68. doi:10.4236/jbbs.2011.12008

http://www.scirp.org/journal/PaperInformation.aspx?pape $\underline{\mathrm{rID}=4630}$

[37] D. Wilkinson, "Drugs for Treatment of Alzheimers' Disease," International Journal of Clinical Practice, Vol. 55. No. 2, 2001, pp. 129-134. http://www.ncbi.nlm.nih.gov/pubmed/11321852

[38] S. Burgmans, M. P. Van Boxtel, E. F. Vuurman, F. Smeets, E. H. Gronenschild, H. B. Uylings and J. Jolles, "The Prevalence of Cortical Gray Matter Atrophy May Be Overestimated In the Healthy Aging Brain," Neuropsychology, Vol. 23, No. 5, 2009, pp. 541-550. doi:10.1037/a0016161 http://www.ncbi.nlm.nih.gov/pubmed/19702408

[39] G. C. Chiang, Ph. S. Insel, D. Tosun, N. Schuff, D. TruranSacrey, S. Raptentsetsang, C. R. Jack and M. W. Weiner, "Identifying Cognitively Healthy Elderly Individuals with Subsequent Memory Decline by using Automated MR Temporoparietal Volumes," Radiology, Vol. 259, No. 3, 2011, pp. 844-851. doi:10.1148/radiol.11101637 http://www.ncbi.nlm.nih.gov/pubmed/21467255

[40] J. C. Morris, "The Clinical Dementia Rating (CDR): Current Version and Scoring Rules," Neurology, Vol. 11, No. 43, 1993, pp. 2412-2414.

http://www.neurology.org/content/43/11/2412.2.full.pdf+ $\underline{\mathrm{html}}$

[41] I. V. Maksimovich, "Method for Endovascular Treatment of Alzheimer's Disease,” Russian Patent, No. 2297860, 2006.

http://worldwide.espacenet.com/publicationDetails/origin alDocument?FT $=\mathrm{D} \&$ date $=20070427 \& \mathrm{DB}=\mathrm{EPODOC} \&$ locale $=$ en $E P \& C C=R U \& N R=2297860 \mathrm{C} 1 \& \mathrm{KC}=\mathrm{C} 1$

[42] I. V. Maksimovich, "Method and Device for Endovascular Treatment of Alzheimer's Disease," Patent US, No. 7389776, 2008.

http://www.freepatentsonline.com/7389776.pdf

[43] I. V. Maksimovich, "Endovascular Procedures in Treatment of the Alzheimer's Disease," Journal Diagnostic and Intervention Radiology, Vol. 3, No. 2, 2009, pp. 23 35.

http://www.radiology-di.ru/articles/158/177/tom-3-N2-20 09.html

[44] I. V. Maksimovich, "Endovascular Low-Energy Laser Radiation Effect on Dyscirculatory Angiopathy of Alzheimer's Type in the Treatment of Alzheimer's Disease,' Journal of Alzheimer's \& Dementia, Vol. 7, No. 4, 2011, pp. S791-S793.

http://www.alzheimersanddementia.com/article/S1552-52 60(11)02427-7/fulltext

[45] A. Venneri, M. F. Shanks, R. T. Staff, et al., "Cerebral Blood Flow and Cognitive Responses to Rivastigmine Treatment in Alzheimer's Disease," Neuroreport, Vol. 13, No. 1, 2002, pp. 83-87. . doi:10.1097/00001756-200201210-00020 http://www.ncbi.nlm.nih.gov/pubmed/11924899

[46] A. Fredriksson, W. Danysz, G. Quack, et al., "Coadministration of Memantine and Amantadine with Sub/supratheshold Doses of L-Dopa Restores Motor Behaviour of MPTP-Treated Mice," Journal of Neural Transmission, Vol. 108, No. 2, 2001, pp. 167-187 doi:10.1007/s007020170086 http://www.ncbi.nlm.nih.gov/pubmed?term=Fredriksson $\% 20 \mathrm{~A} \% 2 \mathrm{C} \% 20$ Danysz $\% 20 \mathrm{~W} \% 2 \mathrm{C} \% 20 \mathrm{Quack} \% 20 \mathrm{G} \% 2 \mathrm{C}$ $\% 20 \mathrm{et} \% 20 \mathrm{al}$

[47] D. Wilkinson, "Drugs for Treatment of Alzheimer's Disease," International Journal of Clinical Practice, Vol. 55, No. 2, 2001, pp. 129-134.

http://www.ncbi.nlm.nih.gov/pubmed/11321852

[48] I. V. Maksimovich, "Transljuminal Laser Angioplasty in Treatment of Ischemic Lesions of a Brain," M.D. Dissertation, Russian University of Friendship of the People, Moscow, 2004. 
http://disseng.com/page/order/id/206426.html

[49] G. K. Chizhov, N. I. Koval'skaia and V. I. Kozlov, "The Effect of Helium-Neon Laser Radiation on the Energy Metabolic Indices of the Myocardium," Biulleten' Eksperimental'noĭ Biologii i Meditsiny, Vol. 111, No. 3, 1991, pp. 302-305.

http://www.ncbi.nlm.nih.gov/pubmed/2054512

[50] V. I. Kozlov and G. A. Aziziv, "Pathophysiological Characteristics of Microcirculatory Disorders in Chronic Arterial Ischaemia of Lower Limbs," Angiology and Vascular Surgery, Vol. 13, No. 7, 2007, pp. 17-23.

http://www.ncbi.nlm.nih.gov/pubmed/17679971
[51] S. V. Moskvin, "System Analysis of Efficiency in Controlling Biological Systems with Low-Energy Laser Radiation," Thesis for Degree of Doctor of Biological Sciences, City of Tula, 2008.

http://www.dissers.info/disser 323120.html

[52] Ch. Heinrich, R. Blum, S. Gascón, et al., "Directing Astroglia from the Cerebral Cortex into Subtype Specific Functional Neurons," PLoS Biology, Vol. 8, No. 5, 2010, p. e1000373. doi:10.1371/journal.pbio. 1000373 http://www.ncbi.nlm.nih.gov/pmc/articles/PMC2872647/ ?tool=pmcentrez 